Jurnal Farmamedika Vol. 1, No. 1 Juni 2016

\title{
KARAKTERISASI NANOVESIKEL TRANSFERSOM SEBAGAI \\ PEMBAWA "RUTIN" DALAM PENGEMBANGAN SEDIAAN TRANSDERMAL
}

\author{
Devi Ratnasari ${ }^{1 *}$, Effionora Anwar ${ }^{2}$ \\ ${ }^{1}$ Program Studi S1 Farmasi, Sekolah Tinggi Teknologi Industri dan Farmasi Bogor \\ ${ }^{2}$ Departemen Farmasetika, Fakultas Farmasi, Universitas Indonesia \\ *Korespondensi: deviratnasarigo@ gmail.com
}

\begin{abstract}
ABSTRAK
Sediaan transdermal dapat menjadi alternatif untuk menghantarkan senyawa yang memiliki kelarutan rendah dalam air atau senyawa dengan ketersediaan hayati yang rendah bila diberikan secara oral.Rutin merupakan salah satu senyawa flavonoid yang banyak terkandung dalam buah semangka, dan jeruk.Rutin menunjukkan absorbsi yang rendah pada konsumsi per oral, sehingga sebagai alternatif dapat diberikan melalui penghantaran transdermal.Berbagai pendekatan dilakukan untuk meningkatkan penetrasi sediaan transdermal salah satunya dengan sistem pembawa nanovesikel.Transfersom merupakan nanovesikel berukuran 200-300 nm yang tersusun dari fosfolipid, surfaktan dan air untuk meningkatkan penetrasi pada penghantaran trasndermal.Penelitian ini bertujuan untuk mengkarakterisasi transfersom yang mengandung rutin yang dibuat dalam berbagai komposisi perbandingan fosfatidilkolin dan surfaktan. Karakteristik dari transfersom yang diperoleh menunjukan ukuran transfersom $<150 \mathrm{~nm}$ dengan indeks polidispersitas berkisar $0,1-0,3$, nilai zeta potensial lebih kecil dari $-30 \mathrm{mV}$ dan nilai efisiensi penjerapan $>80 \%$.
\end{abstract}

\section{Kata Kunci: Flavonoid, Nanovesikel, Rutin, Transdermal, Transfersom}

\begin{abstract}
Transdermal become the alternative to deliver low solubility compound and low bioavalibility when given orally. Rutin is a flavonoid compound are found in watermelon and citrus. Rutin shows a low absorption when administered orally so the alternative is given in the transdermal route. A variety of approaches taken to increase the penetration of transdermal, one with nanovesikel carrier system. Transfersome is nanovesicle 200-300 nm sized composed of phospholipids, surfactants and water to increase penetration in trasndermal route. This study was to characterization transfersome containing rutin. The result show the size of transfersome $<150 \mathrm{~nm}$, polydispersity index about 0.1 to 0.3 , zeta potential less than $-30 \mathrm{mV}$ and entrapment efficiency > $80 \%$.
\end{abstract}

Key Word : Flavonoid, Nanovesicle, Rutin, Transdermal, Transfersom 


\section{PENDAHULUAN}

Sediaan transdermal adalah bentuk sediaan yang sistem pemberiannya mendukung transpor bahan obat dari permukaan kulit melalui epidermis, dermis dan lapisan lainnya sampai ke dalam sirkulasi sistemik [1].Sistem penghantaran transdermal dipilih sebagai alternatif untuk menghantarkan senyawa dengan sifat kelarutan yang rendah dalam air serta senyawa yang memiliki bioavailabilitas rendah bila diberikan secara oral.

Rutin merupakan salah satu senyawa flavonoid yang banyak terkandung dalam buah semangka, dan kulit dari tanaman jenis jeruk.Rutin memiliki berbagai aktivitas farmakologi diantaranya sebagai antiinflamasi, anti artritis reumatoid, vasodilator, dan mencegah agregasi platelet [2].Rutin menunjukan absorbsi yang rendah pada konsumsi per oral, sehingga konsentrasi dalam plasma menjadi sangat rendah. Penelitian yang dilakukan oleh Manach [3], menunjukan bahwa setelah pemberian $500 \mathrm{mg}$ rutin secara oral, kadar rutin yang ditemukan dalam darah setelah 7 jam adalah $0.73 \mu \mathrm{mol} / \mathrm{L}$. Kadar rutin yang rendah di dalam plasma disebabkan karena permeasinya yang rendah pada saluran cerna [4] serta dapat mengalami degradasi oleh mikroba di usus [5]. Penelitian yang menunjukan bahwa rutin diabsorbsi rendah melalui pemberian oral mendasari perlunya dikembangkan penghantaran rutin melalui rute transdermal. Tujuan pemberian sediaan transdermal ini adalah untuk meningkatkan kadar rutin dalam plasma, sehingga efek farmakologi yang diharapkan dapat diperoleh secara maksimal.

Hambatan terbesar dalam penghantaran rute transdermal adalah adanya lapisan stratum korneum pada bagian kulit terluar.Lapisan stratum korneum tersusun secara rapat sehingga sulit ditembus oleh molekul-molekul dari luar [6].Berbagai pendekatan dilakukan untuk meningkatkan penetrasi melewati stratum korneum diantaranya dengan menggunakan sistem pembawa nanovesikel.Nanovesikel merupakan salah satu sistem penghantaran sediaan transdermal yang berbentuk kantung dengan ukuran nanometer.Nanovesikel terdiri dari liposom, niosom, dan tranfersom [6].

Transfersom merupakan nanovesikel yang terdiri dari bagian yang bersifat hidrofil dan hidrofob secara bersamaan yaitu fosfolipid, surfaktan dan air [7].Transfersom dapat menghantarkan obat dengan sifat kelarutan yang bermacam-macam, transfersom juga bersifat elastis sehingga dapat melewati celah yang ukurannya 5 sampai 10 kali lebih kecil tanpa kehilangan bentuknya.Elastisitas dan deformabililitas yang dimiliki transfersom menjadi keunggulannya untuk lebih mudah menembus lapisan kulit, sehingga obat lebih mudah masuk ke dalam sirkulasi sistemik [6].Transfersom sebagai sistem pembawa dalam sediaan transdermal diharapkan mampu meningkatkan penetrasi rutin sampai ke sirkulasi sistemik.

Penelitian ini bertujuan untuk mengkarakterisasi transfersom yang mengandung rutin yang dibuat dalam berbagai komposisi perbandingan fosfatidilkolin dan surfaktan.Karakterisasi meliputi penentuan ukuran partikel, indeks polidispersitas, zeta potensial, efisiensi penjerapan, dan morfologi partikel.

\section{METODE PENELITIAN}

Bahan: Phospholipon 90G (Pemberian GMBH Lipoid Jerman), rutin standar (Sigma Aldrich, USA), rutin (Acetar Bio-Tech Inc, China), karbopol-940 (Lubrizol, Hongkong), metanol p.a (Merck, Jerman), etanol p.a (Merck, Jerman), Tween 80 (Kao Corporation), aqua demineralisata (Brataco, Indonesia), kalium dihidrogen fosfat (Merck, Jerman).

Alat : Rotavapor (Hahn Shin HS-2005S-N), timbangan analitik (Accu Lab), particle size analyzer (Malvern Zetasizer), Kromatografi cair Kinerja Tinggi detektor UV-Vis (Shimadzu , jepang), kolom C18 (250mm x 4,6mm, $5 \mu \mathrm{m})$ fase terbalik (Kromasil), ultrasonikator homogenizer (Biologics, Inc), timbangan analitik, pengaduk magnetic (IKA C-MAG HS 7), homogenizer (Multimax, Malaysia), lemari pendingin (Polytron), penyaring eluen dan sampel (Whatman), mikropipet eppendorf (Socorex).

\section{Metode \\ Pembuatan Transfersom Yang Mengandung Rutin}

Dilakukan optimasi formula transfersom yang mengandung 5\% rutin. Transfersom dibuat dengan menggunakan metode hidrasi lapis tipis.Sejumlah tertentu Fosfatidilkolin dan surfaktan didispersikan dalam etanol, kemudian ke dalam campuran tersebut ditambahkan rutin.Selanjutnya, etanol dievaporasi dengan rotary evaporator pada suhu $40{ }^{\circ} \mathrm{C}$ dan diatur kecepatan putarannya bekisar $60-130$ rpm. Pelarut yang masih tersisa dihilangkan dengan vakum selama semalam dan akan diperoleh lapisan film tipis. Selanjutnya, lapisan film yang terbentuk dihidrasi dengan larutan dapar 
fosfat $\mathrm{pH} 7.4$ dan dirotasi $60 \mathrm{rpm}$ selama 1 jam.Suspensi yang terbentuk kemudian disonikasi dengan kecepatan amplitudo 40\% selama 20 menit.Tujuan sonikasi adalah untuk memperoleh ukuran partikel yang lebih kecil dan homogen. Formulasi transfersom dapat dilihat pada Tabel.1

Tabel 1.Formulasi transfersom yang mengandung $5 \%$ rutin

\begin{tabular}{cc}
\hline Formula & Fosfatidilkolin : Surfaktan \\
\hline I & $90: 10$ \\
II & $85: 15$ \\
III & $70: 30$ \\
\hline
\end{tabular}

\section{Evaluasi Transfersom}

Distribusi ukuran partikel dan Indeks Polidispersitas

Pengukuran distribusi ukuran partikel transfersom menggunakan Particle Size Analyzer (PSA). Larutan aquades digunakan sebagai baseline, kemudian sebanyak $10 \mathrm{~mL}$ sampel dimasukkan ke dalam kuvet, setelah itu akan terukur partikel gobul-globul transfersome dan indeks polidispersitas.

\section{Potensial Zeta}

Besarnya potensial zeta suatu partikel dapat digunakan untuk prediksi kestabilan transfersom.Potensial zeta diukur menggunakan alat zeta sizer.Suspensi transfersom diencerkan menggunakan air destilasi.Sebanyak $10 \mathrm{~mL}$ sampel yang telah diencerkan dimasukkan secara perlahan-lahan ke dalam kuvet khusus.Sampel dalam kuvet harus dipastikan bahwa tidak ada gelembung.Kuvet dimasukkan ke dalam alat dan diukur zeta potensial.

\section{Efisiensi Penjerapan (\% EE)}

Efisiensi penjerapan (\% EE) transfersom ditentukan dengan menggunakan ultrasentrifugator pada kecepatan $9500 \mathrm{rpm}$ pada suhu $4^{\circ} \mathrm{C}$ selama $3 \times 30$ menit. Setelah ultrasentifugasi akan diperoleh bagian endapan dan supernatan. Kemudian $250 \mu \mathrm{L}$ supernatan dilarutkan dalam dapar fosfat $\mathrm{pH} 7.4$ dan ditentukan kadarnya menggunakan kromatografi cair kinerja tinggi menggunakan kolom fase terbalik, fase gerak air:etanol (1:1) pada panjang gelombang $257 \mathrm{~nm}$. Efisiensi penjerapan dihitung berdasarkan persamaan berikut :

Efisiensi Penjerapan =

$$
\frac{\text { Total obat }- \text { Obat bebas }}{\text { Total obat }} \times 100 \%
$$

\section{Morfologi Bentuk Vesikel}

Karakteristik morfologi dan ukuran vesikel transfersom dapat diketahui dengan menggunakan Transmission Electron Microscopy (TEM).Tahapan pengerjaan TEM adalah dengan meneteskan sampel pada carbon coated cooper grid sebanyak satu tetes sampai terbentuk lapisan tipis kemudian ditambahkan satu tetes phosphotungsticacid $1 \%$. Selanjutnya sampel dikeringkan dan diamati bentuk vesikelnya.

\section{HASIL DAN PEMBAHASAN \\ Pembuatan Transfersom}

Transfersom dibuat dalam tiga komposisi berbeda dengan membandingkan jumlah fosfatidilkolin dan tween 80.Perbandingan antara fosfatidilkolin dan tween 80 yang digunakan adalah $(90: 10), \quad(85: 15)$ dan (70:30).Hal ini ditujukan untuk mengetahui pengaruh perbandingan fosfatidilkolin dan tween 80 terhadap karakteristik transfersom [2].Metode yang digunakan dalam pembuatan transfersom adalah hidrasi lapis tipis kemudian dilanjutkan dengan sonikasi probe.Dipilihnya kombinasi kedua metode ini bertujuan untuk memperoleh ukuran partikel yang lebih kecil dan homogen serta nilai efisiensi penjerapan yang tinggi [9].

Kecepatan rotary evaporator yang terlalu tinggi pada proses pembuatan transfersom dapat menyebabkan distribusi panas tidak merata sehingga sulit terbentuk lapisan yang tipis dan merata[8], sehingga pada penelitian ini rotavapor diputar secara bertahap mulai dari 60 rpm (rate per minute) sampai $130 \mathrm{rpm}$. Kondisi vakum diperlukan dalam pembuatan lapis tipis transfersom karena membantu mempercepat penguapan pelarut. Lapis tipis yang terbentuk harus merata pada dinding labu agar pada saat proses hidrasi seluruh lapisan dapat kontak dengan dapar fosfat $\mathrm{pH}$ 7,4 sehingga lapis tipis mudah terkelupas dan tidak ada bahan yang tersisa di labu. Setelah dibuat lapis tipis kemudian disimpan dalam lemari pendingin selama 24 jam untuk menyempurnakan pembentukan vesikel transfersom. 
Pada proses hidrasi lapis tipis dilakukan dalam keadaan tidak vakum dan dibantu dengan glass beads untuk membantu pengelupasan dan membuat suspensi lebih homogen. Setelah tahap hidrasi lapis tipis dilanjutkan dengan sonikasi. Sonikasi banyak digunakan dalam proses pengecilan ukuran partikel karena melibatkan suatu interaksi fisikokimia yang memecah aglomerat. Secara umum terdapat dua tipe ultrasonikator yang dapat digunakan untuk memecah partikel yang beraglomerasi yaitu ultrasonikator tipe langsung (probe) dan ultrasonikator tipe tidak langsung (bath). Pada ultrasonikator tipe tidak langsung, gelombang ultrasonik yang dihasilkan harus mampu melewati cairan dalam bath dan menembus dinding wadah dari sampelsedangkan pada ultrasonikator tipe langsung, probe dapat dimasukan ke dalam sampel sehingga mengurangi hambatan fisik untuk menghantarkan gelombang[9].

\section{Distribusi Ukuran Partikel dan Indeks Polidispersitas Transfersom}

Distribusi ukuran partikel diukur menggunakan Particle Size Analyzer (PSA). Hasil pengukuran menunjukan transfersom dari ketiga formula berukuran $<150 \mathrm{~nm}$. Transfersome dengan ukuran lebih kecil dari $400 \mathrm{~nm}$ akan lebih mudah berpenetrasi melewati lapisan kulit[11]. Tabel 2 menunjukan hasil distribusi ukuran partikel transfersom.

Tabel 2. Data ukuran partikel suspensi transfersom rutin

\begin{tabular}{llll}
\hline Parameter & $\begin{array}{l}\text { F1 } \\
(\mathbf{n m})\end{array}$ & $\begin{array}{l}\text { F 2 } \\
(\mathbf{n m})\end{array}$ & $\begin{array}{l}\text { F3 } \\
(\mathbf{n m})\end{array}$ \\
\hline Z-average & 104,90 & 87,16 & 70,68 \\
$\begin{array}{l}\text { Indeks } \\
\text { Polidispersitas }\end{array}$ & 0,375 & 0,389 & 0,138 \\
\hline
\end{tabular}

Penentuan ukuran partikel didasarkan pada prinsip DLS (Dynamic Light Scaterring) yang mengukur gerak Brown suatu partikel. Nilai Zaverage menunjukan rata-rata ukuran partikel transfersom.Berdasarkan hasil penelitian, formula III memiliki nilai Z-average lebih kecil dibandingkan Formula I dan formula II.Indeks polidispersitas merupakan parameter yang menunjukan keseragaman ukuran partikel dalam suatu sampel. Pada penelitian ini diperoleh nilai indeks polidispersitas antara 0,1 sampai 0,3 yang menunjukan bahwa partikel dalam suspensi homogen ( 0,0 sangat homogen dan 1,0 sangat heterogen) [12]. Perolehan nilai indeks polidispersitas menunjukan bahwa formula III memiliki nilai yang paling kecil, hal ini menunjukan bahwa formula III merupakan formula yang paling homogen.Komposisi yang tepat antara fosfatidilkolin, surfaktan dan jumlah bahan aktif dapat menentukan distribusi ukuran partikel [13].Data yang diperoleh pada penelitian ini menunjukan bahwa peningkatan jumlah surfaktan yang diikuti dengan penurunan jumlah fosfatidilkolin menunjukan ukuran partikel yang lebih kecil dan distribusi partikel yang lebih homogen.

\section{Potensial Zeta}

Potensial zeta ditentukan berdasarkan pergerakan elektroforesis yaitu pergerakan relatif partikel yang disebabkan adanya muatan elektrik.Potensial zeta merupakan teknik untuk menentukan muatan permukaan pada koloid nanopartikel.Nanopartikel memiliki muatan permukaan yang mampu menarik lapisan tipis ion yang memiliki muatan berlawanan ke permukaan nanopartikel. Lapisan ion ganda ini akan berada di sekitar permukaan ion nanopartikel dan dapat berdifusi ke seluruh larutan. Potensial listrik pada batas antara dua lapisan ganda ini dikenal dengan potensial zeta partikel.Besarnya potensial zeta suatu partikel dapat digunakan untuk prediksi kestabilannya. Nilai potensial zeta suatu nanopartikel yang lebih besar dari $+30 \mathrm{mV}$ atau lebih kecil dari $30 \mathrm{mV}$ menunjukan derajat kestabilan yang tinggi. Partikel dalam suspensi yang memiliki nilai potensial zeta lebih besar dari $-/+30 \mathrm{mV}$ akan saling tolak menolak satu sama lain sehingga tidak ada kecenderungan untuk terflokulasi[14]. Dispersi dengan nilai zeta potensial yang rendah akan membentuk agregat karena dapat terjadi gaya tarik-menarik melalui ikatan Van der Wall[15].

Faktor yang paling penting dalam perolehan nilai zeta potensial adalah $\mathrm{pH}$. Jika suatu partikel dengan muatan negatif, kemudian kedalamnya ditambahkan senyawa basa maka muatannya menjadi lebih negatif dan apabila ditambahkan senyawa asam maka muatan 
16 | Devi Ratnasari, et.al.( Karakterisasi Nanovesikel ...)

negatifnya akan dinetralisir. Gambaran kurva zeta potensial Vs $\mathrm{pH}$ akan positif bila suspensi berada pada $\mathrm{pH}$ rendah dan menjadi negatif bila berada pada $\mathrm{pH}$ yang tinggi[14].

Pada penelitian ini diperoleh nilai zeta potensial yang negatif karena $\mathrm{pH}$ suspensi transfersom berkisar 7,4 satuan $\mathrm{pH}$. Suspensi transfersom yang terbentuk menunjukan nilai potensial zeta yang lebih kecil dari $-30 \mathrm{mV}$.Hal ini menunjukan bahwa ketiga formula memiliki derajat kestabilan yang baik. Formula III memiliki nilai potensial zeta yang paling kecil dan berarti memiliki kestabilan yang paling tinggi dibandingkan formula yang lain. Tabel 3 menunjukan hasil penentuan potensial zeta ketiga formula suspensi transfersom:

\section{Tabel 3. Data zeta potensial suspensi transfersom rutin}

\begin{tabular}{cc}
\hline \multirow{2}{*}{ Formula } & Zeta Potensial $(\mathbf{m V})$ \\
\hline I & $-31,7$ \\
II & $-30,3$ \\
III & $-48,3$ \\
\hline
\end{tabular}

\section{Efisiensi Penjerapan}

Efisiensi penjerapan merupakan evaluasi yang dilakukan untuk mengetahui jumlah obat yang terjerap di dalam transfersom.Efisiensi penjerapan ditentukan dengan melakukan pemisahan antara obat yang terjerap dengan obat bebas menggunakan metode sentrifugasi[1].Efisiensi penjerapan dapat digunakan sebagai parameter utama dalam menentukan formula terpilih pada pembuatan nanovesikel. Sebelum menentukan nilai efisiensi penjerapan, perlu ditentukan kandungan rutin total (rutin yang terdapat dalam suspensi) dan kandungan rutin bebas (rutin yang tidak terjerap dalam transfersom). Jumlah rutin bebas diperoleh dengan melakukan pemisahan menggunakan ultrasentrifugasi pada kecepatan $9.500 \mathrm{rpm}$ selama 1,5 jam pada suhu $\quad 4^{\circ} \mathrm{C}$. Tabel 4 menunjukan hasil efisiensi penjerapan ketiga formula transfersom. Efisiensi penjerapan paling tinggi ditunjukan oleh formula III, hal ini menunjukan bahwa jumlah rutin yang terjerap dalam nanovesikel pada formula III lebih banyak dibandingkan formula I dan II.

Tabel 4. Data efisiensi penjerapan transfersom rutin

\begin{tabular}{cc}
\hline Formula & Efisiensi Penjerapan (\%) \\
\hline I & $82,91 \pm 2,43$ \\
II & $84,45 \pm 0,28$ \\
III & $89,00 \pm 0,41$ \\
\hline
\end{tabular}

\section{Morfologi bentuk vesikel}

Pengamatan menggunakan Transmission Elcetronic Microscope (TEM) dilakukan pada perbesaran 20.000x. Pengamatan ini bertujuan untuk mengetahui morfologi dari transfersom, selain itu melalui pengamatan TEM akan terlihat agregasi antar nanovesikel transfersom. 


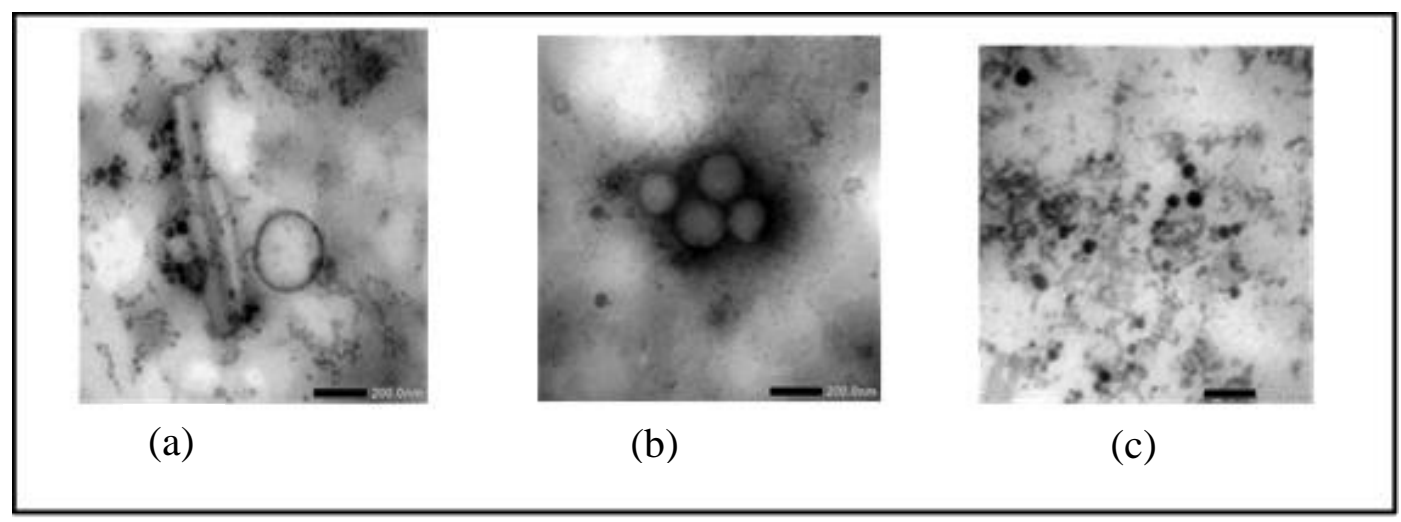

Gambar 1. Hasil pengamatan bentuk vesikel dengan TEM perbesaran 20.000x (a) Formula I (b) Formula II (c) Formula III

Hasil pengamatan dengan TEM terlihat bentuk vesikel yang sferis pada ketiga formula.Pada formula I dan formula III tidak nampak agregasi antar globul, sebab pada formula tersebut nilai potensial zeta cukup besar yang menandakan kestabilan globul.Pada formula II nampak ada agregasi, hal ini sesuai dengan data potensial zeta bahwa formula II memiliki nilai potensial zeta yang paling kecil.

Berdasarkan data pada tabel 4, formula III memiliki efisiensi penjerapan yang paling besar dibandingkan formula lainnya.Beberapa penelitian yang pernah dilakukan oleh Abdallah[16] dan Patel[13]menunjukan bahwa dengan meningkatnya jumlah surfaktan dalam transfersom menyebabkan peningkatan nilai efisiensi penjerapan.

\section{SIMPULAN}

Transfersom yang dibuat dengan membandingkan tiga komposisi fosfatidilkolin:surfaktan yaitu 90:10, 85:15, dan 70:30 menunjukan karakteristik transfersom yang baik. Hal ini dibuktikan dengan melihat hasil evaluasi distribusi ukuran partikel, zeta potensial, dan nilai efisiensi penjerapan yang secara keseluruhan memenuhi kriteria sebagai nanovesikel. Formula III dengan kandungan surfaktan paling tinggi menunjukan karakteristik transfersom yang paling baik, hal ini dibuktikan dengan nilai indeks polidispersitas paling rendah yaitu 0,138 dan nilai potensial zeta paling tinggi yaitu $-48,3$ yang menunjukan derajat kestabilan paling baik. Selain itu, nilai efisiensi penjerapan rutin dalam transfersom dari formula III juga menunjukan yang paling tinggi yaitu sebesar $89 \%$.

\section{SARAN}

Transfersom yang terbentuk perlu dikembangkan dalam suatu sediaan farmasi serta dilakukan uji penetrasi untuk mengetahui kemampuan penetrasi transfersom sebagai sistem pembawa obat pada sediaan transdermal.

\section{DAFTAR PUSTAKA}

[1] Prajapati, S.T., Patel, C.G., Patel, C.N. 2011. Transfersomes: A Vesicular Carrier System for Transdermal Drug Delivery. Asian Journal of Biochemical and Pharmaceutical Research. 2 (1): 121-128.

[2] Zielinska, D., Nowak, D.S., Zielinski, H. 2010. Determination of The Antioxidant Activity of Rutin and its Contribution to The Antioxidant Capacity of Diversifed Buckwheat Origin Material by Updated Analytical Strategies. Polish Journal of Food and Nutrition Sciences. 40: 315-321

[3] Manach, C., Morand, C., Demigne, C., Texier, O, Regerat, F., Remesy, C. 1997. Bioavailability of Rutin and Quercetin in Rats. FEBS Letters. 409: 12-16.

[4] Mauludin, R., Muller, R.H., Keck, C.M. 2008. Kinetic Solubility and Dissolution Velocity of Rutin Nanocrystals. European Journal of Pharmaceutical Science. 36:502-510.

[5] Shimoi, K., Yoshizumi,K., Kido, T., Usui, Y., Yumoto, T. 2003. Absorption and Urinary Excretion of Quercetin, Rutin and $\alpha$-G-Rutin, a Water Soluble Flavonoid in Rats. Journal of Agricultural and Food Chemistry. 51: 2785-2789.

[6] Walve, J.R., Bakliwal, S.R., Rane B.R., Pawar S.P. 2011. Transfersomes: A Surrogated Carrier for Transdermal Drug Delivery System. International Journal of 
18 | Devi Ratnasari, et.al.( Karakterisasi Nanovesikel ...)

Applied Biology and Pharmaceutical Technology. 2(1).

[7] Gupta, P.N., Mishra, V., Rawat, A., Dubey, P., Mahor, S., Jain, S., Chatterji, D.P., Vyas, S.P. 2005. Non-Invasive Vaccine Delivery in Transfersomes, Niosomes and Liposomes: a Comparative Study. International Journal of Pharmaceutic. 293: 73-82.

[8] Varshneya, A., Ravikumar, P. 2015. Formulation and Characterization of Rutin Trihydrate Liposomes for Topical Delivery. Internaional Journal of Pharmaceutical Research.

[9] Taurozzi, J.S., Hackley, V.A., Wiesner, M.R. 2010. Protocol for Preparation Nanoparticle Dispersion from Powdered Material Using Ultrasonic Disruption. National Institute for Standard and Technology. United State of America.

[10] Hadian, Z., Sahari, M., Moghimi, H.R., Barzegar, M. 2014. Formulation, Characterization and Optimation of Liposome Containing Eicosapentaenoic and Docosahexaenoic Acids; a Methodology Approach. International Journal of Pharmaceutical Research, 13 (2): 393-404.

[11] Barry, Brian., W, Elka., Couitoo. 2007. Enhancement in Drug Delivery. CRC Press, Taylor \& Francis Group. United States

[12] Saraf, S., Jeswani, G., Kaur, C.D., Saraf, S. (2011). Development of Herbal Cosmetic Cream With Curcuma Longa Extract Loaded Transfersomes for Antiwrinkle Effect. African Journal of Pharmacy and Pharmacology. 5 (8): 1056-106 